\title{
Doação de órgãos: é preciso educar para avançar
}

\author{
Organ donation: you need to educate to advance
}

Taise Ribeiro Morais'1, Maricelma Ribeiro Morais²

'Especialista em Saúde Pública pela Faculdade de Ciências Médicas (FCM) Campina Grande (PB), Brasil. taise_morais@hotmail.com

${ }^{2}$ Mestre em Meio Ambiente pela Universidade Federal da Paraíba (UFPB) - João Pessoa (PB) - Brasil.

maricelma.ribeiro@gmail.com
RESUMO $O$ estudo refere-se a uma das principais dificuldades encontradas no processo de doação de órgãos: a deficiência de educação continuada específica para doação por parte da população e dos profissionais de saúde. Teve como objetivo enfatizar como a educação influi positivamente nas estatísticas de doações de órgãos. Trata-se de uma revisão bibliográfica, incluindo artigos de periódicos eletrônicos e obras literárias. Existe uma grande diferença entre o número de pessoas esperando transplante e o número de doadores. Medidas de educação contínua e políticas de saúde pública que incentivem as pessoas a manifestar o desejo de serem doadoras são estratégias importantes para amenizar esse problema.

PALAVRAS CHAVE: Transplante de órgãos; Educação Continuada; Promoção da Saúde.

ABSTRACT The study refers to one of the main difficulties encountered in the process of organ donation: the deficiency of specific continuing education for donations by the general public and health professionals. Aimed to emphasize how education affects positively the statistics of organ donations. This is a literature review, including electronic journal articles and literary wor$\mathrm{ks}$. There is a big difference between the number of people waiting for transplant and the number of donors. Measurements of continuing education and public health policies that encourage people to express their desire to be donors are important strategies to alleviate this problem.

KEYWORDS: Organ transplantation; Continuing education; Promotion of health. 


\section{Introdução}

O transplante de órgãos humanos e a doação de órgãos são temas polêmicos que têm despertado interesse e discussóes em várias comunidades. A falta de esclarecimento, o noticiário sensacionalista sobre tráfico de órgãos, a ausência de programas permanentes voltados para a conscientizaçáo da população e o incentivo à captação de órgãos contribuem para alimentar dúvidas e arraigar mitos e preconceitos (NEUMANN, 1997).

Talvez, por essas razóes, haja número insuficiente de doadores e grande perda de potenciais doadores, prolongando o sofrimento de pacientes que dependem da doação de órgãos, condenando-os a permanecer em uma interminável lista de espera (MORAES, GALLANI; MENEGHIN, 2006).

A doaçẫo de órgãos e tecidos é vista pela sociedade, em geral, como um ato de solidariedade e amor dos familiares. No entanto, ela exige a tomada de decisão num momento de extrema dor e angústia motivadas pelo impacto da notícia da morte, pelo sentimento de perda e pela interrupção inesperada de uma trajetória de vida (ALENCAR, 2006).

Hoje, com a modificaçáo dos critérios de morte, surgem o conceito de morte encefálica e a possibilidade de utilização de órgãos e tecidos do doador. Quando não há uma boa compreensão do processo da doação de órgãos, os familiares dos possíveis doadores sentem-se apreensivos, em dúvida e indecisos no momento da ocorrência, por ser um assunto sobre o qual não têm muito esclarecimento (ALENCAR, 2006).

Os objetivos do presente estudo são realizar uma revisão bibliográfica sobre fatores associados à educação específica para doação de órgãos e enfatizar como um maior nível de conhecimento do tema influi de forma positiva nas estatísticas de doaçôes de órgãos.

\section{Metodologia}

Este trabalho é uma revisão bibliográfica do tipo descritiva que inclui 14 artigos de periódicos eletrônicos e obras literárias, publicados ao longo dos últimos anos.

Para seleção dos artigos estudados, analisamos vários artigos científicos e obras literárias pertinentes ao tema. O critério de escolha foi a abordagem dos subtemas nos quais se divide este estudo: transplante de órgãos, educação em saúde, doação e captação de órgãos.

Para captação dos resultados, realizamos um levantamento e uma comparação entre opiniôes dos 14 artigos selecionados, de diversos autores, fazendo com que a análise documental do assunto permita delinear um quadro generalista e com riqueza de informaçóes a respeito de cada subtema.

\section{Como funciona a captação de órgãos}

Identificação do potencial doador: um potencial doador é o paciente que se encontra internado em um hospital, sob cuidados intensivos, por injúria cerebral severa causada por acidente com traumatismo craniano, derrame cerebral, tumor e outros, com subsequente lesão irreversível do encéfalo.

Notificação: quando existe a identificação de um potencial doador em unidade de terapia intensiva ou pronto socorro, há a obrigatoriedade de notificação compulsória à Central de Notificação, Captação e Distribuição de Órgãos e Tecidos (CNCDO), descentralizadas em OPOs (Organização de Procura de Órgãos). Assim, os profissionais de uma unidade de terapia intensiva têm o compromisso ético de notificar um potencial doador à CNCDO de seu estado.

Avaliação: a OPO se dirige ao Hospital, avalia o doador com base na história clínica, nos antecedentes médicos e exames laboratoriais, na viabilidade dos órgãos e na sorologia, para afastar a possibilidade de doenças infecciosas; e testa a compatibilidade com prováveis receptores. A família é consultada sobre a doação.

Informação do Doador Efetivo: terminada a avaliação, quando o doador é viável, a OPO informa a Central de Transplantes e passa as informaçóes colhidas.

Seleçáo dos Receptores: a Central de Transplantes emite uma lista de receptores inscritos, selecionados em seu cadastro técnico, e compatíveis com o doador. 
Identificação das Equipes Transplantadoras: a Central de Transplantes informa as equipes transplantadoras sobre a existência do doador e qual paciente receptor foi selecionado na lista única em que todos são inscritos por uma equipe responsável pelo procedimento do transplante.

Retirada dos Órgáos: as equipes fazem a extração dos órgãos no hospital onde se encontra o doador, em centro cirúrgico, respeitando todas as técnicas de assepsia e preservação dos órgãos. Terminado o procedimento, elas se dirigem aos hospitais para procederem à transplantação;

Liberação do Corpo: o corpo é entregue à família condignamente recomposto.

\section{Aceitação da população e fatores associa- dos à doação}

A recusa familiar representa um grande entrave à realização dos transplantes, contribuindo para que o número de doadores seja insuficiente para atender à demanda crescente de receptores em lista de espera, sendo também apontada como um dos grandes fatores responsáveis pela escassez de órgãos e tecidos para transplantes (JACOB et al, 1996).

As famílias que compreendem bem o diagnóstico de morte encefálica são mais favoráveis à doação de órgãos em comparação com as famílias que acreditam que a morte só ocorre após a parada cardíaca. Estas geralmente manifestam dificuldades em aceitar a condição de morte do ente querido (SMIRNOFF; MERCER; ARNOLD, 2003).

A divulgaçáo e o esclarecimento são de fundamental importância para que a população possa criar uma consciência sobre a doação de órgãos, e os meios de comunicação têm um papel relevante nesse processo (MORAES; GALLANI; MENEGHIN, 2006).

Os meios de comunicação de massa (televisão, rádio, jornais, revistas) são os principais veiculadores de informaçóes acerca do transplante e da doação de órgãos para a população. Além disso, uma parcela da sociedade é influenciada por indivíduos com os quais se relaciona e por campanhas que incentivam o aumento da doação de órgãos (CONESA et al, 2004).

A literatura é pródiga em referências, demonstrando que os meios massivos de comunicação, apesar de sua grande penetração em âmbito nacional e mundial, não são os mais adequados para promover esclarecimento suficiente sobre temas polêmicos, como é o caso da doação de órgãos. Ao contrário, muitas vezes, a forma, a simbologia e o repertório utilizados pelos meios de comunicação de massa causam mais celeuma e confusão que esclarecimentos (MORAES; GALLANI; MENEGHIN, 2006).

Estudo realizado na Espanha constatou que muitas informaçóes provenientes da mídia, que poderiam ser um caminho para o esclarecimento de dúvidas, por vezes, reproduzem informaçóes distorcidas, superficiais e preconceituosas, sendo, desta forma, incapazes de modificar comportamentos negativos relacionados à doação de órgãos. Foi observado que a negativa de consentimento à doação de órgãos pode ser mais facilmente modificada através da implementação de encontros específicos, campanhas escolares e orientações pelos profissionais de saúde (CONESA et al, 2005).

Ressaltamos aqui a importância da discussão do assunto 'doação de órgãos' com amigos e familiares, pois as pessoas, quando bem instruídas a respeito do tema, são capazes de promover discussóes, o que pode ser considerado como promoção de doação.

Escolaridade também é uma variável importante, sendo que pessoas com nível de escolaridade maior parecem ter uma melhor aceitação sobre doação de órgãos (CONESA et al, 2005).

$\mathrm{O}$ indivíduo contrário à doação de órgãos aparece em estudos como sendo: homem ou mulher com idade acima de 45 anos, com baixo nível educacional, que não entende ou não conhece o conceito de morte encefálica, que tem parceiro contra a doação de órgãos, que não é favorável à doação de sangue e tem medo da manipulação do corpo (cadáver) após a morte. As razóes principais para não ser doador foram o desconhecimento de como ser doador e o medo de diagnóstico errado de morte (MARTINEZ; MARTI; LOPEZ, 1995). 


\section{Apresentando os motivos de recusa da doação de órgãos e tecidos para transplante}

Estudo desenvolvido por Moraes e Massarollo (1995) apontou que os principais motivos de recusa da doação dos órgãos são:

\section{A crença religiosa}

Foi desvelado que a religiáo é considerada como sendo um dos motivos para recusar a doação dos órgãos e tecidos para transplante.

\section{À espera de um milagre}

A crença em Deus alimenta a esperança da família de que um milagre possa acontecer. A crença de que Deus possa ressuscitar ou abençoar o paciente com um milagre é tão grande que o familiar, mesmo quando tem ciência da morte encefálica, prefere acreditar que o paciente vai melhorar.

\section{A não compreensão do diagnóstico de morte encefálica} e a crença na reversáo do quadro

A falta de entendimento da família sobre a morte encefálica dificulta a assimilação de que uma pessoa possa estar morta quando está com suporte avançado de vida. Nessa circunstância, o consentimento da doação dos órgãos é interpretado pela família como sendo o mesmo que assassinar, decretar ou autorizar a morte do parente.

\section{A não aceitação da manipulaçáo do corpo}

O familiar tem dificuldade em aceitar a manipulação do corpo do parente com a finalidade de retirada de órgãos para transplante, e a não aceitação é motivo para negar a doação, por acreditar que o corpo é o templo sagrado de Deus e, portanto, intocável.

\section{O medo da reação da família}

O familiar favorável à doação desconsidera a sua intenção de doar por medo da repressão por parte de outro membro da família.

A inadequaçáo da informaçáo e a ausência de confirmaçáo da morte encefálica

A ausência de confirmação do diagnóstico de morte encefálica e o desencontro das informações transmitidas à família pela equipe do hospital geram dúvidas sobre o quadro do paciente e são motivos para que aquela se recuse a doar os órgãos.

\section{A desconfiança na assistência e o medo do comércio de órgáos}

Há a crença de que a morte do parente possa ser antecipada ou induzida objetivando a doação dos órgáos.

\section{A inadequaçáo do processo de doaçáo}

A solicitação da doação dos órgãos pela equipe médica, quando feita antes da confirmação do diagnóstico, é motivo de revolta e indignação para os familiares.

A família, quando se sente cobrada pela equipe para autorizar a doação dos órgãos, fica desconfiada e recusa a doação, mesmo lamentando não respeitar o desejo do falecido de ser um doador.

$\mathrm{O}$ desejo do paciente falecido, manifestado em vida, de não ser um doador de órgãos

É respeitado o desejo do falecido, manifestado em vida, de não ser um doador de órgãos, sendo considerado pelo familiar que o importante é acatar o desejo do ente querido, mesmo que para algumas pessoas a vontade do paciente, depois de morto, não tenha importância ou que o ato de recusar a doação pareça uma atitude egoísta.

\section{O medo da perda do ente querido}

Foi desvelado que o familiar expressa o medo da perda negando a doação dos órgãos.

\section{Algumas estratégias de incentivo à doa- ção de órgãos}

Educação para profissionais e estudantes da área da saúde

Quando falamos em educação como uma forma de incentivo à doação de órgãos, não devemos nos deter apenas à população. A educação dos profissionais de saúde, específica para a doação de órgãos, é fator decisivo tanto para o refinamento técnico do transplante quanto para a melhora do índice de captação de órgáos. Existem na literatura médica evidências de conhecimento 
insuficiente dos profissionais de saúde brasileiros sobre o tema transplante de órgáos, o que pode justificar o baixo nível de captação de órgãos em nosso meio (AMARAL et al, 2002).

Pesquisa realizada com pessoas que frequentavam postos de saúde na Espanha apontou que apenas 7\% das pessoas receberam informaçóes sobre transplante de profissionais da atenção primária à saúde; o restante, de outros veículos. Foi observado que, quando o paciente recebia uma informação negativa sobre transplantes por um profissional da saúde, esse tipo de informação causava o pior impacto sobre a aceitação da doação. Por outro lado, quando esses mesmos profissionais forneciam informação positiva sobre os transplantes, havia um claro aumento das reaçóes positivas, mais importantes que as provenientes de outras fontes (89\% e 65\%, respectivamente) (TRAIBER; LOPES, 2006).

Estima-se que somente 15 a $20 \%$ dos potenciais doadores de órgãos se tornam doadores efetivos. Existe a ideia de que a escassez do número de doaçóes é fruto da falta de doadores ou da alta taxa de recusa de doaçôes pelos familiares, mas esses dados revelam que não há uma absoluta falta de doadores, porém, de doaçóes. Ou seja, embora ainda haja a crença de que o motivo para a não doação está na falta de potenciais doadores, é descrito em estudos que, antes da recusa por parte dos familiares, um dos maiores empecilhos à doação de órgãos recai sobre os profissionais de saúde (SILVA, 2004).

A negativa de consentimento por parte da família poderia ser contornada mais facilmente se os profissionais envolvidos no processo de captação esclarecessem de forma competente as dúvidas daquela. Infelizmente, muitos profissionais não estão preparados para responder a questionamentos sobre a doação. Outro fator a ser considerado é a classificação incorreta dos órgãos e tecidos que, por essa razão, são rejeitados, diminuindo o número de transplantes (ESPÍNDOLA et al, 2007).

Os profissionais da saúde têm papel importante na divulgação de informação sobre doação de órgãos, pois têm acesso a grande parte da população e causam impacto maior que outros meios de comunicação nas atitudes com relação ao tema. Campanhas de esclarecimento deveriam ocorrer dentro das próprias instituições, com a participação de médicos, enfermeiras, técnicos de enfermagem e todos os outros profissionais que trabalham no hospital. O mesmo deveria acontecer em postos de saúde, clínicas e hospitais menores. Essas campanhas deveriam disponibilizar informação clara e específica a respeito dos conceitos básicos de morte encefálica, doação de órgãos, custo de doação, aparência do corpo após a retirada de órgãos, aspectos éticos, experiências da família do doador e do receptor, entre outras orientaçóes, pois essas pessoas, como são formadoras de opinião, influenciam os pacientes e seus familiares (TRAIBER; LOPES, 2006).

\section{Incentivo à discussáo dentro das famílias}

Pesquisas realizadas com famílias de doadores de órgáos demonstram que um fator importante para essa decisão foi a discussão prévia sobre doação entre os familiares.

Estudo realizado na cidade de Pelotas (RS), que avaliou uma amostra de 3159 adultos, através de questionário, demonstrou que $80,1 \%$ dos participantes seriam favoráveis à doação de órgãos de um familiar seu, caso este houvesse manifestado previamente o desejo de ser doador. Em contrapartida, apenas um terço dos investigados autorizaria a doação se não houvesse uma discussão prévia com a família (BARCELLOS; ARAUJO; COSTA, 2005).

Uma pesquisa canadense que investigou familiares de pacientes que evoluíram para morte encefálica em nove hospitais constatou algumas diferenças entre famílias de doadores e de não doadores. Familiares de pacientes jovens, do sexo masculino, com morte associada a trauma, apresentavam maior probabilidade de consentir com a doação. O fato de a família ter discutido sobre doação com o paciente ou acreditar que o paciente desejaria ser doador, mesmo sem ter tido uma discussão explícita sobre o assunto, foi fortemente associado ao consentimento para doação de órgãos neste estudo (SMIRNOFF; MERCER; ARNOLD, 2003).

Infere-se que campanhas que incentivem as pessoas a discutir sobre doação de órgãos e transplantes com seus familiares são fundamentais. 


\section{Conclusões}

O baixo nível de escolaridade e a desinformação da população podem gerar interpretações deturpadas a respeito da captação e do transplante de órgãos. Segundo os princípios da bioética, indivíduos mal informados sobre o tema em questão não são capazes de decidir conscientemente se desejam realizar a doação dos órgãos de seu ente falecido.

As informaçóes veiculadas pelos meios de comunicação de massa não têm sido suficientes nem eficientes para modificar tal panorama; ao contrário, reforçam o imaginário popular repleto de mitos, crendices e desinformaçóes sobre a atividade relacionada aos transplantes no Brasil e no mundo.

Diante de toda a problemática que envolve o processo saúde-doença do ser humano, a atividade educativa é uma oportunidade de troca de experiências das pessoas entre si e com os profissionais de saúde, possibilitando-lhes o acesso a informaçóes e a trocas de vivências pessoais, tão comumente carregadas de conflitos e dificuldades que interferem na escolha de doar ou não os órgãos do ente falecido.

Frente a essa realidade, o profissional de saúde deve atuar como educador, para modificar a opiniâo pública quanto aos conceitos errôneos; mas as crenças desfavoráveis só poderão ser modificadas se os educadores estimularem a população a participar de debates sobre transplantes de órgãos e legislação.

Modificar a realidade existente implica, também, desenvolver programas planejados e avaliados dentro de um processo educativo contínuo, respaldado por referenciais teóricos e modelos cientificamente reconhecidos destinados a todos os segmentos da comunidade.

Portanto, faz-se necessária uma exortação ao poder público, para que esse considere a falta de insumos à prática da doação de órgãos como um problema real e inclua as atividades educativas acerca de transplantes nos programas prioritários de governo e nas políticas de atenção à saúde.

\section{Referências}

ALENCAR, S.C.S. Doação de órgãos e tecidos: a vivência dos familiares de crianças e adolescentes doadores. 161 f. 2006. Dissertação (Mestrado em Enfermagem) - Universidade Federal do Paraná Paraná, 2006.

AMARAL, A.S. et al. Knowledge of organ donation among one group of Brazilian professors of medicine. Transplantation Proceedings, Houston, v.34, n. 2, p. 449-450, mar. 2002.

BARCELLOS, F.C.; ARAUJO, C.L.; COSTA, J.D. Organ donation: a population-based study. Clinical Transplantation, Hoboken, v. 19, p. 33-37,fev. 2005.

CONESA, C. et al. Influence of different sources of information on attitude toward organ donation: a factor analysis. Transplantation Proceedings,Houston, v.36, n. 5, p.1245-1248, jun. 2004.

Multivariate study of the psychosocial factors affecting public attitude towards organ donation. Nefrologia, Santander, v.25, n.6, 2005.
ESPÍNDOLA, R.F. et al. Conhecimento de estudantes de medicina sobre o processo de doação de córneas. Arquivo Brasileiro de Oftalmologia, São Paulo, v.70, n.4,p.581,584, jul./ago. 2007.

JACOB, F. et al. Regional awareness campaing concerning organ sharing. Transplantation Proceedings, Houston, v.28,n.1, p. 393, 1996.

MARTINEZ, J.M.; MARTI, A.; LOPEZ, J.S. Spanish public opinion concernig organ donation and transplantation. Medicinal Clinic, Barcelona, v. 105, n.11, p.401-406, 1995.

MORAES, E.L.; MASSAROLLO, M.C.K.B. Recusa de doação de órgãos e tecidos para transplante relatados por familiares de potenciais doadores. Acta paulista de enfermagem, São Paulo, v.22, n.2, 2009. Disponível em: <http://www.scielo.br/scielo.php?script=sci_arttex t\&pid=S010321002009000200003> Acesso em: 13 mar.2012.

MORAES, M.W.; GALLANI, M.C.B.J.; MENEGHIN, P. Crenças que influenciam adolescentes na doação de órgãos. Revista da Escola de Enfermagem da USP, São Paulo, v.40, n.4, p. 484-492dez. 2006. 
NEUMANN, J. Transplante de órgãos e tecidos. São Paulo: Sarvier; 1997. 465p.

SILVA, J.N. Identificação e notificação de doadores de órgãos e tecidos em Terapia Intensiva. 2004. Monografia. Santa Catarina: Universidade Federal de Santa Catarina, 2004.
SMIRNOFF, L.A.; MERCER, M.B.; ARNOLD, R. Families understanding of brain death. Program Transplant, Progress in Transplantation, Arlington,v. 13, n.3, p.218-224, set. 2003.

TRAIBER, C.; LOPES, M.H.I. Educação para doação de órgãos. Scientia Medica, Porto Alegre, v. 16, n. 4, p.178-182, out./dez 2006.

Recebido para publicação em Abril/2012 Versão definitiva em Novembro/2012

Suporte financeiro: não houve

Conflito de interesse: inexistente 